\title{
Anatomic study of the morphology of the right and left coronary arteries
}

\author{
S. Singh, N. Ajayi, L. Lazarus, K.S. Satyapal \\ Department of Clinical Anatomy, School of Laboratory Medicine and Medical Sciences, College of Health Sciences, \\ Westville Campus, University of Kwazulu-Natal, Durban, South Africa
}

[Received: 29 August 2016; Accepted: 6 October 2016]

\begin{abstract}
Arising from the aorta, the right (RCA) and left (LCA) coronary arteries provide the arterial supply to both the atria and the ventricles of the heart. An extensive literature review revealed that most studies have either evaluated the morphology of the RCA or the LCA independently. This study aimed to document the relationship between the morphology of the RCA and LCA using coronary angiograms. In addition, variations such as split or double $R C A$ and an absent $L C A$ were documented. A review of 500 coronary angiograms was conducted and the RCA and LCA were classified according to their branching patterns and arterial dominance. The most prevalent branching pattern of the LCA was bifurcation (in $65.8 \%$; $329 / 500)$, while trifurcation and quadrifurcation occurred in 20.4\% (102/500) and $1.6 \%$ (8/500), respectively. The LCA was absent in $11.8 \%$ (59/500) of cases with the bifurcation and trifurcation of its branches in 10.8\% (54/500) and 1.4\% (7/500), respectively. The splitting of the RCA occurred in $4.2 \%$ (21/500) of the angiograms. A split RCA with concomitant absent $L C A$ was documented in $1.2 \%$ (6/500) of the angiograms. The RCA and LCA were dominant in $77.2 \%$ (386/500) and $9.8 \%$ (49/500) of cases, respectively, whereas co-dominance occurred in $13 \%$ (65/500) of the sample examined. In most cases where a split RCA was present, the $R C A$ was found to be non-dominant. With the advent of coronary arteriography, a comprehensive understanding of coronary arterial anatomy and their anomalies has become essential. (Folia Morphol 2017; 76, 4: 668-674)
\end{abstract}

Key words: right coronary artery, left coronary artery, split right coronary artery, absent left coronary artery

\section{INTRODUCTION}

The heart has its own unique arterial supply provided by the coronary arteries [24]. Branching from the aorta, the right (RCA) and left (LCA) coronary arteries supply the myocardium and epicardium of the heart [24]. Arising from the right aortic sinus, the RCA descends in the coronary sulcus [23]. The RCA gives off a right marginal branch, running towards the apex of the heart, before proceeding to the posterior aspect of the heart [24]. The RCA then passes through the crux (interatrial and interventricular junction) of the heart and gives rise to the posterior interventricular branch (PIB), before terminating in the coronary sulcus [24].

Arising from the left aortic sinus, the LCA traverses the coronary sulcus for a short distance before dividing into two or three branches at the atrioventricular groove $[24,29]$. The anterior interventricular branch (AIB) of the LCA runs towards the apex and gives off a diagonal branch. The circumflex branch (CX)

Address for correspondence: Prof. K.S. Satyapal, School of Laboratory Medicine and Medical Sciences, College of Health Sciences, Westville Campus, University of Kwazulu-Natal, Private Bag X54001, Durban, 4000, South Africa, tel: +27 312607899 ; fax: +27 312607890 , e-mail: satyapalk@ukzn.ac.za 
of the LCA gives off a left marginal branch and then terminates on the posterior aspect before reaching the crux [24]. The coronary artery from which the PIB arises is referred to as the dominant artery, and it is usually the RCA (60\%) [29]. Codominance (2.5\%) occurs when both the CX and the RCA provide a PIB [6]. The posterior part of the ventricular septum and often part of the posterolateral wall of the left ventricle is supplied by the PIB [29].

One of the rarest congenital anomalies of the coronary arteries is the double or split RCA $[2,10]$. There is still controversy with respect to the definition and correct diagnosis of the split RCA [2]. The double or split RCA has been described by several proposed concepts [10].

Gupta et al. [17] was the first to report incidence of a double RCA. In their study, the two vessels arose from separate adjacent coronary ostia with the smaller vessel providing the PIB and the larger vessel continuing as the right marginal branch [23]. Nair et al. [26] described a double RCA arising from a single coronary ostium where both vessels of the RCA ran parallel in the right atrioventricular groove and crossed the crux of the heart. In 2007, Kunimasa et al. [22] described a double RCA arising from a single ostium and supplying blood to the interventricular septum. Both vessels coursed in the interventricular sulcus but did not cross the crux. Lemburg et al. [23] described a true double RCA, of which both vessels had similar diameters and originated from two separate adjacent coronary ostia in the right coronary sinus.

Double RCA were also described as two separate branches of the RCA in the atrioventricular groove running closely together for half the course of the RCA [23]. In addition, the double RCA can originate from a single proximal trunk or separate orifices from the right aortic sinus and can exhibit two distinct PIBs or a single PIB [25]. Sawaya et al. [27] and Andreou [5] described the double or split RCA as containing only split portions of the PIB, not two RCAs, with separate proximal courses.

Certain geometric features may predispose vasculature to atherogenesis due to their effect on the local flow field [13]. Two different geometric shapes of the RCA, viz. C-shaped and sigma-shaped ( $S$-shaped), have been described using coronary angiography [13, 16]. C-shaped RCA's have been found to be associated with atherosclerosis in their proximal-middle region [13]. In this proximal-middle area, the flow pattern is characterised by low shear stress along the inner wall and maximal difference of shear stress between the inner and outer walls hence making it an apt environment for the formation of atherosclerotic plaques [13]. Dvir et al. [13] found C-shaped RCA's to be more associated with atherosclerosis than S-shaped RCA's due to the geometrical disposition of the $C$-shaped RCA.

The LCA usually divides into two branches; however, a third branch known as the median or intermedian artery is known to exist $[7,11]$. The median artery can arise from the LCA or the proximal part of the AIB or CX arteries [7, 11]. It traverses the sternocostal surface of the left ventricle and is distributed around the middle area between the base and apex of the heart $[7,11]$.

Isolated absence of the LCA occurs when the AIB and $C X$ arteries arise directly from the left aortic sinus as opposed to bifurcating from a common trunk [6]. The distribution patterns of the vessels are otherwise normal and this anomaly is more prevalent in the presence of aortic valvular disease and LCA dominance $[20,31]$. Instances where the AIB and CX arteries originate outside the left coronary sinus or ectopically is known as secondary absence of the LCA [6].

This study aimed to document the relationship between the morphology of the RCA and LCA, including their branching patterns and the shape of the RCA. In addition, the prevalence of an absent LCA and split or double RCA will be documented using coronary angiograms.

\section{MATERIALS AND METHODS}

This retrospective study included a review of 500 human coronary angiograms acquired from the cardiac catheterisation laboratory of a private hospital in KwaZulu Natal, Durban, South Africa. Of these angiograms, 293 were males and 207 were females with a racial distribution of 354 Indian, 103 white and 43 black patients. The branching patterns of the LCA and RCA were documented, including coronary arterial dominance. The RCA was divided into types using an original classification system formulated by the authors. The types were classified according to the absence or presence of a split RCA and the arterial dominance. RCA type $A$ occurred when a single RCA was present, type $B$ was a split RCA with left dominance, type $C$ was a split RCA with co-dominance and type $D$ was a split RCA with right dominance. The LCA was classified into types adapted from Tomar et al. [30], and Chougule et al. [11]. The types were classified according to the branching pattern and 
Table 1. Classification types of right coronary artery (RCA) and left coronary artery (LCA)

\begin{tabular}{|c|c|c|c|c|c|c|c|}
\hline $\begin{array}{l}\text { RCA } \\
\text { types }\end{array}$ & Description & Schematic diagram & $\begin{array}{c}\text { Incidence } \\
(\%)\end{array}$ & $\begin{array}{l}\text { LCA } \\
\text { types }\end{array}$ & Description & Schematic diagram & $\begin{array}{c}\text { Incidence } \\
(\%)\end{array}$ \\
\hline Type A & Single RCA & & 96 & Type A & $\begin{array}{c}\text { Present } \\
\text { bifurcation }\end{array}$ & & 65.8 \\
\hline Type B & $\begin{array}{c}\text { Split left } \\
\text { dominance }\end{array}$ & & 3.4 & Type B & $\begin{array}{l}\text { Present } \\
\text { trifurcation }\end{array}$ & & 20.4 \\
\hline Type C & $\begin{array}{c}\text { Split co- } \\
\text { dominance }\end{array}$ & & 0.4 & Type C & $\begin{array}{l}\text { Present } \\
\text { quadri- } \\
\text { furcation }\end{array}$ & & 1.6 \\
\hline \multirow[t]{2}{*}{ Type D } & $\begin{array}{c}\text { Split right } \\
\text { dominance }\end{array}$ & RCA & 0.2 & Type D & $\begin{array}{c}\text { Absent } \\
\text { bifurcation }\end{array}$ & & 10.8 \\
\hline & & & & Type E & $\begin{array}{c}\text { Absent } \\
\text { trifurcation }\end{array}$ & & 1.4 \\
\hline
\end{tabular}

AIB — anterior interventricular branch; CX — circumflex artery; PIB — posterior interventricular branch; MA — median artery

the absence or presence of the LCA. The LCA type A occurred when the LCA bifurcated into AIB and CX arteries; type $B$ occurred when the LCA trifurcated into AIB, median and CX arteries; type $C$ was categorised as quadrifurcating into $\mathrm{AIB}$, two median arteries and a CX artery; type D occurred when the LCA was absent and the AIB and CX arteries originated separately from the aortic sinus and type $E$ occurred when the LCA was absent and the AIB, median and CX arteries arose from the left aortic sinus.

The shape of the RCA was also documented and classified as either C-shaped or S-shaped adopted from Gungor et al. [16]. The relationship of the anatomy of the RCA and LCA was evaluated. In addition, the presence of coronary variations such as double or split RCA and absent LCA was documented. The RCA was classified as double or split when two separate branches of the RCA were found running together for at least half the course of the RCA [23]. A split RCA could originate from either a single proximal trunk or separate orifices [25].

\section{Statistical analysis}

Statistical analysis was performed using Stata 13.0 SE (StataCorp. 2013). Stata Statistical Software: Release 13. College Station, TX: StataCorp LP). Pearson's $\chi^{2}$ test was implemented and a $p$ value of less than 0.05 was deemed statistically significant. Ethical clearance was obtained from the Biomedical Research Ethics Committee of the University of Kwazulu-Natal (BE044/15).

\section{RESULTS}

The RCA and LCA were each classified into types according to their branching patterns, arterial dominance and the absence or presence of the LCA and split RCA (Table 1).

\section{Right coronary artery}

A single RCA (type A) was present in $95.8 \%$ (479/500) and a split RCA was found in $4.2 \%(21 / 500)$ of cases. Type B (split RCA with left dominance) occurred in $3.6 \%(18 / 500)$ of cases. type C (split RCA 

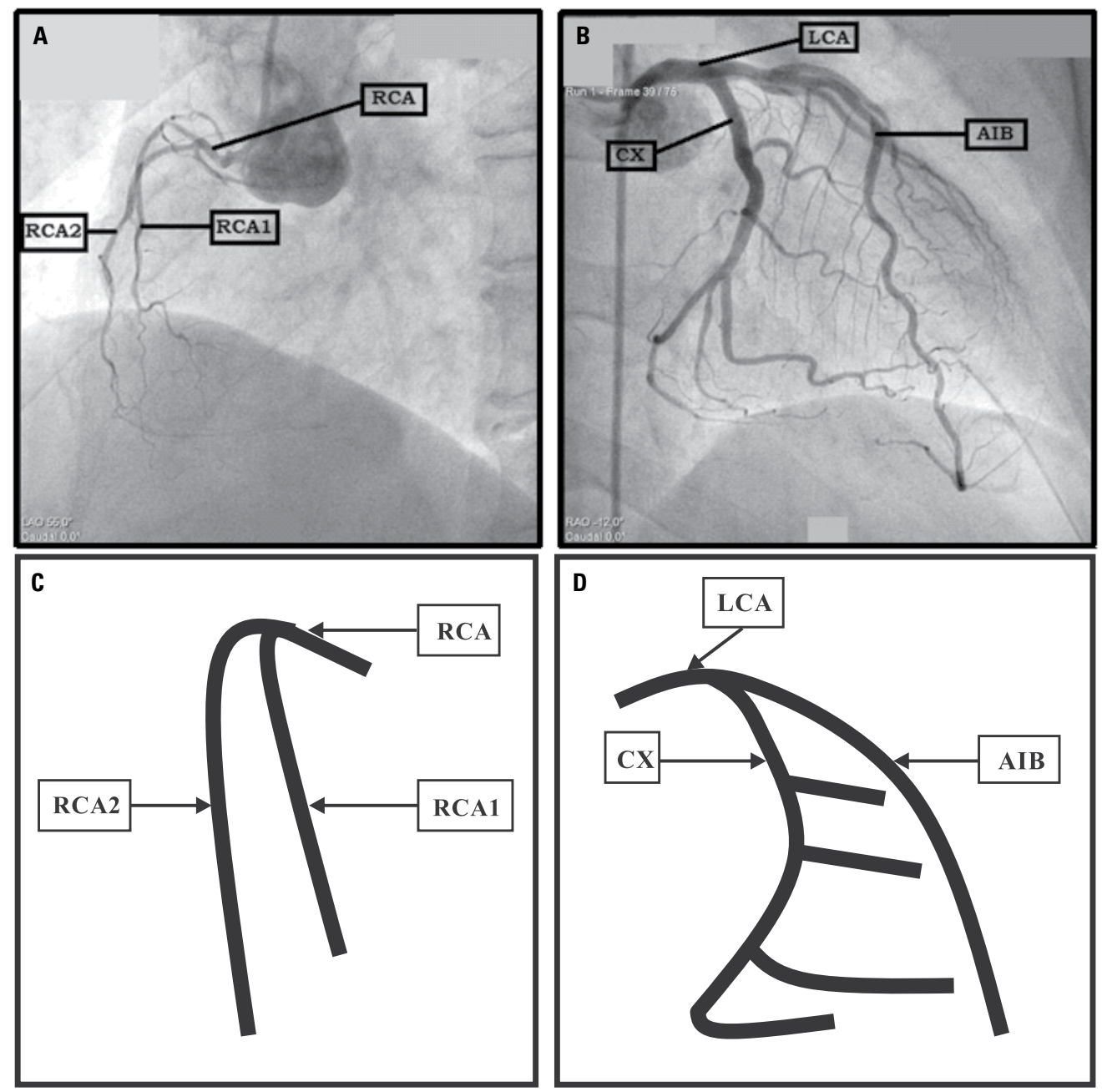

Figure 1. Angiographic images showing a split right coronary artery (RCA) (A) and present left coronary artery (LCA) (B). Corresponding schematic diagram representing a split RCA (C) and present LCA (D); RCA1 — right coronary artery 1; RCA2 — right coronary artery 2; CX — circumflex artery; AIB — anterior interventricular branch.

with co-dominance) was present in $0.4 \%(2 / 500)$ of cases, while type $\mathrm{D}$ (split RCA with right dominance) occurred in $0.2 \%(1 / 500)$ of cases (Table 1$)$.

\section{Left coronary artery}

The LCA was present in $88.2 \%(441 / 500)$ and absent in $11.8 \%(59 / 500)$ of the sample examined. The LCA was divided into types according to its branching patterns, arterial dominance and absence or presence of the LCA. When the LCA was present, LCA type A (bifurcation of the LCA) occurred in $65.8 \%$ (329/500) of cases. Type B (trifurcation of the LCA) occurred in $20.4 \%(102 / 500)$ of cases and type $C$ (quadrifurcation of the LCA) had a prevalence of $1.6 \%(8 / 500)$. When the LCA was absent, type D (bifurcation) occurred in $10.8 \%(54 / 500)$ of cases and type $E$ (trifurcation) was recorded in $1.4 \%(7 / 500)$ (Table 1$)$. When the LCA was present, split RCA occurred in 3.4\% (15/441) and when the LCA was absent, split RCA occurred in $10.2 \%(6 / 59)$.

In $85.2 \%(426 / 500)$ angiograms, a single RCA occurred with an LCA presenting normal coronary anatomy. This occurred in $87 \%$ (255/293) males and $84 \%(174 / 207)$ females. A single RCA with an absent LCA occurred in $10.6 \%(53 / 500)$ of the angiograms and this occurred in $10.2 \%$ (30/293) males and $11 \%$ (23/207) females. The splitting of the RCA with the LCA present occurred in 3\% (15/500) angiograms (Fig. 1). This occurred in 8 males and 4 females. The concomitant splitting of the RCA with an absent LCA occurred in $1.2 \%(6 / 500)$ of the angiograms (Fig. 2). This occurred in 1 male and 5 females. With respect to the shape of the RCA, 68\% (340/500) was found to be $C$-shaped and 32\% (160/500) S-shaped. C-shaped occurred in 66.6\% (195/293) males and 

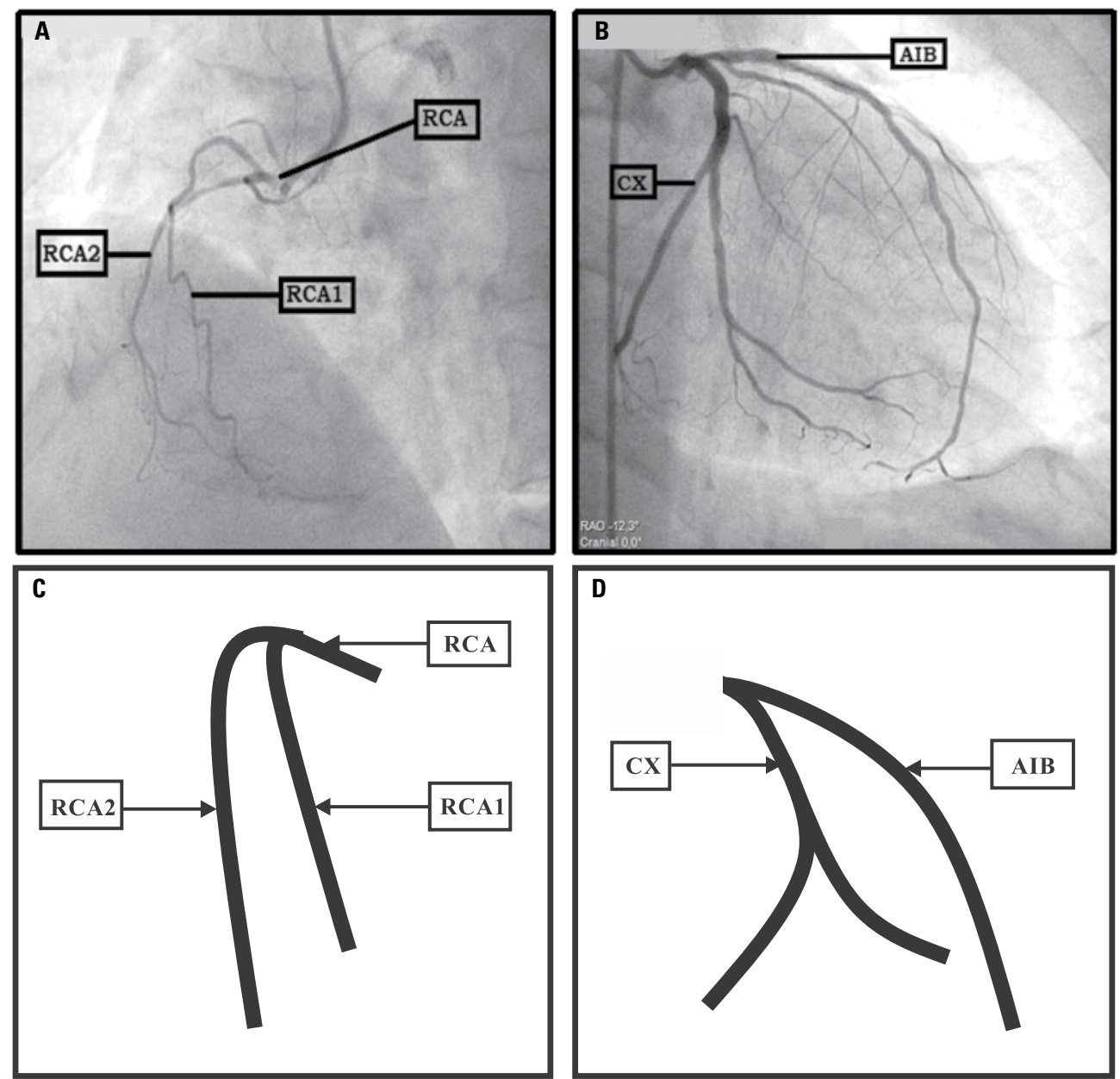

Figure 2. Angiographic images showing a split right coronary artery (RCA) (A) and absent left coronary artery (LCA) (B). Corresponding schematic diagrams representing a split RCA (C) and absent LCA (D); RCA1 — right coronary artery 1; RCA2 — right coronary artery 2; CX — circumflex artery; AIB — anterior interventricular branch.

$70 \%(145 / 207)$ females and $S$-shaped occurred in $33.4 \%(98 / 293)$ males and $29.9 \%(62 / 207)$ females.

The Pearson $\chi^{2}$ test between the absence or presence of a split RCA and the absence or presence of the LCA presented a $p$ value of 0.015 . The $\chi^{2}$ test between a split RCA and gender and race revealed $p$ values of 0.554 and 0.063 , respectively. The $\chi^{2}$ test between the absence or presence of the LCA and gender and race revealed $p$ values of 0.314 and 0.772 , respectively (Table 2).

\section{DISCUSSION}

An extensive literature review revealed that most studies have either evaluated the anatomic variations of the RCA or LCA independently. This study found an incidence of $4.2 \%$ for double or split RCA which corresponded more closely to Angelini et al. [6], who documented $1.23 \%$, than Erbagci et al. [14], and
Table 2. Data analysis showing results of Pearson chi square $\left(\chi^{2}\right)$ tests

\begin{tabular}{lc}
\hline Variables & Pearson $\chi^{2}$ test $(\mathbf{p})$ \\
\hline Absence or presence of split RCA & 0.015 \\
and absence or presence of LCA & \\
Split RCA and gender & 0.554 \\
Split RCA and race & 0.063 \\
Absence or presence of LCA and gender & 0.314 \\
Absence or presence of LCA and race & 0.772 \\
\hline
\end{tabular}

LCA - left coronary artery; RCA — right coronary artery

Kunimasa et al. [22], who found $0.01 \%$ and $0.07 \%$, respectively. Due to its rarity, the split RCA is more frequently described in case reports (Table 3 ).

The incidence of absent LCA in the present study was $11.8 \%$. This was similar to the study by Ajayi et al. 
Table 3. Incidence of double or split right coronary artery (RCA)

\begin{tabular}{lcc}
\hline Author (year) & Sample size & $\begin{array}{c}\text { Incidence of } \\
\text { double/split } \\
\text { RCA (\%) }\end{array}$ \\
\hline Angelini et al. (1999) [6] & 1950 & 1.23 \\
Harikrishnan et al. (2001) [17] & 1 case report & - \\
Altun et al. (2002) [4] & 2 case reports & - \\
Harikrishnan et al. (2002) [18] & 7400 & 0.01 \\
Erbagci et al. (2006) [14] & 1 case report & - \\
Kunimasa et al. (2007) [21] & 2957 & 0.07 \\
Gulel et al. (2007) [15] & 1 case report & - \\
Sawaya et al. (2008) [26] & 1 case report & - \\
Akcay et al. (2010) [2] & 1 case report & - \\
Selcoki et al. (2010) [27] & 2 case reports & - \\
Present study & 500 & 4.2 \\
\hline
\end{tabular}

Table 4. Incidence of absent left coronary artery (LCA)

\begin{tabular}{lcc}
\hline Author (year) & Sample size & $\begin{array}{c}\text { Incidence of } \\
\text { absent LCA }\end{array}$ \\
\hline llia et al. (1998) [19] & 126595 & 0.41 \\
Angelini et al. (1999) [6] & 1950 & 0.67 \\
Cankaya et al. (2009) [9] & 1 case report & - \\
Kosar et al. (2009) [20] & 700 & 0.4 \\
Ajayi et al. (2015) [1] & 407 & 9.6 \\
Present study & 500 & 11.8 \\
\hline
\end{tabular}

[1] who reported an incidence of $9.6 \%$ of an absent LCA. However, this incidence is considerably higher than Yamanaka et al. [31] (0.41\%), Angelini et al. [6] $(0.47 \%)$ and Altin et al. [3] (0.9\%) (Table 4).

This study, however, aimed to investigate the RCA in conjunction with the LCA, with a focus on a split RCA and absent LCA. The Pearson $\chi^{2}$ test showed that there is a significant correlation between the split RCA and absent LCA $(p<0.05)$. A split RCA occurred more often in the absence $(10.2 \%)$ than the presence (3.4\%) of the LCA. Bogers et al. [8] showed that coronary vessels develop by ingrowth towards their orifices on the ascending aorta which differs from the previous assumption that coronary arteries are formed by outgrowths from the aorta and the systemic venous sinus, respectively. Ajayi et al. [1] suggested that the high prevalence of split RCA in hearts with absent LCA may be due to the occurrence of the fast ingrowth of the primitive coronary vascular network in both the left and right coronary vascular tree. The branches of the RCA may have joined to form a single trunk while approaching the right coronary ostium due to fast ingrowth in such hearts. The present study corroborated their finding with the significant correlation between the absent LCA and split RCA.

The normal anatomy of the coronary arteries was present in $85.2 \%$ of hearts and the right coronary system provided the most prevalent arterial dominance which was $70.4 \%$. Single RCA with an absent LCA was found in $10.6 \%$ of the angiograms and the RCA was dominant in $6.6 \%$. The presence of the LCA with the splitting of the RCA occurred in $3 \%$ of the angiograms and the LCA was dominant in $1.8 \%$ of these angiograms. The concomitant absence of the LCA with splitting of the RCA was present in $10.2 \%$ of the angiograms with absent LCA. In these cases, left dominance was observed in all hearts and this variation was observed in more females (83.3\%) than males (16.6\%). This was lower than Ajayi et al. [1], who found $20.5 \%$ of hearts presenting a split RCA with and an absent LCA. This study found left dominance to be more prevalent in the presence of a double or split RCA (85.7\%).

With regard to the shape of the RCA, $68 \%$ was found to be $C$-shaped and $32 \% \mathrm{~S}$-shaped. This was similar to the result of Demirbag and Yilmaz [12] who found $65.7 \%$ C-shaped and $34.3 \%$ S-shaped. It differed with the report of Dvir et al. [13], who recorded $S$-shaped to be more prevalent than $C$ shaped (30\% C-shaped and 70\% S-shaped) as well as Gungor et al. [16], who found a higher incidence of C-shaped (84.9\% C-shaped and 15.1\% S-shaped). $C$-shaped RCAs have been found to be associated with atherosclerosis and coronary artery disease $[13,16]$. Dvir et al. [13] in 2003 postulated that the bend in the middle region of an S-shaped RCA accounts for a different hemodynamic pattern, and consequently a lower susceptibility to atherosclerotic disease.

\section{CONCLUSIONS}

This study found a significant correlation between split RCA and absent LCA with the splitting of the RCA more prevalent in the absence than presence of the LCA. With the advent of coronary angiography and cardiopulmonary bypass surgery in-depth knowledge of coronary arterial anatomy and associated anomalies is of great importance. 


\section{REFERENCES}

1. Ajayi NO, Lazarus L, Vanker EA, et al. Absent left main coronary artery with variation in the origin of its branches in a South African population. Anat Histol Embryol. 2015; 44(2): 81-85, doi: 10.1111/ahe.12109, indexed in Pubmed: 24660977.

2. Akcay A, Koroglu S, Kaya $\mathrm{H}$, et al. An unusual appearance of double right coronary artery. Cardiol Res Pract. 2010; 2010, doi: 10.4061/2010/123846, indexed in Pubmed: 20936138.

3. Altin C, Kanyilmaz $S$, Koc $S$, et al. Coronary anatomy, anatomic variations and anomalies: a retrospective coronary angiography study. Singapore Med J. 2015; 56(6): 339-345, doi: 10.11622/smedj.2014193, indexed in Pubmed: 25502334.

4. Altun A, Akdemir O, Erdogan O, et al. An interesting diagnostic dilemma: double right coronary artery or high take off of a large right ventricular branch. Int J Cardiol. 2002; 82(1): 99-102, indexed in Pubmed: 11786170.

5. Andreou AY. Split right coronary artery. J Cardiovasc Med (Hagerstown). 2010; 11(5): 399-400, doi: 10.2459/ JCM.0b013e328335757c, indexed in Pubmed: 20010109.

6. Angelini P, Villason S, Chan AV, Diez JG. Coronary Artery Anomalies: A Comprehensive Approach. Lippincott Williams \& Wilkins, (Wolters Kluwer) 1999: 27-79.

7. Beg MRU, Singh A, Goel S, et al. 2015. Anatomical variations of coronary artery and frequency of median artery: A cadaveric study from Northern India. Int Arch Integ Med. 2015; 2(5): 88-94.

8. Bogers A, Groot ACGd, Poelmann RE, et al. Development of the origin of the coronary arteries, a matter of ingrowth or outgrowth? Anat Embryol. 1989; 180(5): 437-441, doi: 10.1007/bf00305118.

9. Yilmaz-Cankaya B, Kantarci M, Yalcin A, et al. Absence of the Left Main Coronary Artery: MDCT Coronary Angiographic Imaging. Eurasian J Med. 2009; 41(1): 56-58, indexed in Pubmed: 25610065.

10. Chen YF, Chien TM, Chen CW, et al. Double right coronary artery or split right coronary artery? Int J Cardiol. 2012; 154(3): 243-245, doi: 10.1016/j.ijcard.2011.10.053, indexed in Pubmed: 22078976.

11. Chougule P, Silotry N, Chavan L. Variation in branching pattern of coronary arteries. Int J Scien Res. 2014; 3(8): 2277-8179.

12. Demirbag R, Yilmaz R. Effects of the shape of coronary arteries on the presence, extent, and severity of their disease. Heart Vessels. 2005; 20(5): 224-229, doi: 10.1007/ s00380-005-0837-5, indexed in Pubmed: 16160905.

13. Dvir D, Kornowski R, Gurevich J, et al. Degrees of severe stenoses in sigma-shaped versus C-shaped right coronary arteries. Am J Cardiol. 2003; 92(3): 294-298, indexed in Pubmed: 12888136.

14. Erbagci H, Davutoglu V, Turkmen S, et al. Double right coronary artery: review of literature. Int J Cardiovasc Imaging. 2006; 22(1): 9-11, doi: 10.1007/s10554-005-5139-6, indexed in Pubmed: 16362174.

15. Gulel O, Yazici M, Durna K, et al. A rare coronary anomaly: double right coronary artery. Clin Cardiol. 2007; 30(6): 309, doi: 10.1002/clc.20009, indexed in Pubmed: 17551955.

16. Güngör B, Alper AT, Ozcan KS, et al. Presence of sigma shaped right coronary artery is an indicator of poor prognosis in patients with inferior myocardial infarction treated with primary percutaneous coronary interven- tion. Catheter Cardiovasc Interv. 2014; 84(6): 965-972, doi: 10.1002/ccd.25388, indexed in Pubmed: 24402881.

17. Gupta S, Abraham A, Reddy N, et al. Supernumerary right coronary artery. Clin Cardiol. 1987; 10(7): 425-427, indexed in Pubmed: 3608263.

18. Harikrishnan S, Bhat A, Tharakan JM. Double right coronary artery. Int J Cardiol. 2001; 77(2-3): 315-316, indexed in Pubmed: 11393136.

19. Harikrishnan S, Jacob SP, Tharakan J, et al. Congenital coronary anomalies of origin and distribution in adults: a coronary arteriographic study. Indian Heart J. 2002; 54(3): 271-275, indexed in Pubmed: 12216922.

20. Ilia R, Weinstein JM. Separate origins of left anterior descending, left circumflex and intermediate arteries from the left coronary aortic sinus. Int J Cardiol. 1998; 66(3): 313-315, indexed in Pubmed: 9874085.

21. Koşar $P$, Ergun $E$, Oztürk $C$, et al. Anatomic variations and anomalies of the coronary arteries: 64-slice CT angiographic appearance. Diagn Interv Radiol. 2009; 15(4): 275-283, doi: 10.4261/1305-3825.DIR.2550-09.1, indexed in Pubmed: 19957241.

22. Kunimasa $T$, Sato $Y$, Ichikawa $M$, et al. MDCT detection of double right coronary artery arising from a single ostium in the right sinus of Valsalva: report of 2 cases. Int J Cardiol. 2007; 115(2): 239-241, doi: 10.1016/j.ijcard.2006.01.060, indexed in Pubmed: 16766059.

23. Lemburg SP, Peters SA, Scheeler M, et al. Detection of a double right coronary artery with 16-row multidetector computed tomography. Int J Cardiovasc Imaging. 2007; 23(2): 293-297, doi: 10.1007/s10554-006-9114-7, indexed in Pubmed: 16924401.

24. Moore KL, Dalley AF, Agur AMR. Clinically Oriented Anatomy. Sixth Edition. Lippincott Williams and Wilkins, (Wolters Kluwer) 2010: 144-147.

25. Misuraca L, Balbarini A. Double right coronary artery or split right coronary artery: the same anomaly? J Cardiovasc Med (Hagerstown). 2010; 11(5): 398, doi: 10.2459/JCM.0b013e328337d882, indexed in Pubmed: 20168239.

26. Nair K, Krishnamoorthy KM, Tharakan JA. Double right coronary artery with anomalous origin of septal arteries from the right coronary sinus. Int J Cardiol. 2005; 101 (2): 309-310, doi: 10.1016/j.ijcard.2004.01.031, indexed in Pubmed: 15882682.

27. Sawaya FJ, Sawaya JI, Angelini P. Split right coronary artery: its definition and its territory. Tex Heart Inst J. 2008; 35(4): 477-479, indexed in Pubmed:19156248.

28. Selcoki Y, Yilmaz OC, Er O, et al. Double right coronary artery: a report of two cases. Clinics (Sao Paulo). 2010; 65(4): 449-451, doi: 10.1590/S1807-59322010000400016, indexed in Pubmed: 20454505.

29. Standring S, Borley NR, Collins P, et al. Gray's Anatomy, The Anatomical Basis of Clinical Practice. Fortieth edition. Elsevier, Churchill Livingstone 2009: 2847-2854.

30. Tomar S, Aga P, Sharma PK, et al. 2013. Normal and variant anatomy of left coronary artery: 64 slice multi detector computed tomography (MDCT) coronary angiographic depiction in North Indian population. Int J Scien Res Publications. 2013; 3(8): 1-17.

31. Yamanaka O, Hobbs RE. Coronary artery anomalies in 126,595 patients undergoing coronary arteriography. Cathet Cardiovasc Diagn. 1990; 21(1): 28-40, indexed in Pubmed: 2208265. 